\title{
THE ASSOCIATION BETWEEN THE MEDITERRANEAN DIET AND HIGH PHYSICAL ACTIVITY AMONG THE WORKING POPULATION IN CROATIA
}

\author{
Sandra Pavičić Žeželj’1, Gordana Kenđel Jovanović ${ }^{1}$, Greta Krešić ${ }^{2}$ \\ ${ }^{1}$ Teaching Institute of Public Health of Primorsko-Goranska County, Rijeka, Croatia \\ Department of Health Ecology \\ ${ }^{2}$ University of Rijeka, Opatija, Croatia \\ Faculty of Tourism and Hospitality Management, Department of Food and Nutrition
}

\begin{abstract}
Background: Unhealthy eating habits and physical inactivity constitute an emerging public health problem. The working population is of special interest for public health monitoring and evaluation because workers' unhealthy lifestyles may lead to reduced work ability. The aim of this study was to determine diet quality and adherence to the Mediterranean diet (MD), according to the level of physical activity, and to detect variables associated with the working population's being highly physically active. Material and Methods: At the Institute for Occupational Medicine 400 full-time workers were examined for obesity factors, filled in the short version of International Physical Activity Questionnaire (IPAQ-short) and a validated food frequency questionnaire for adherence to the Mediterranean diet using Mediterranean Diet Score (MDS). The workers were divided into low, moderate and high physical activity groups according to the IPAQ-short scoring protocol. Hierarchical linear regression was performed to determine the variables associated with being highly active. Results: One-third of the participants were highly physically active and their diet adhered to the $\mathrm{MD}\left(\mathrm{Me}_{\mathrm{MDS}}=7\right)$. Significant variables associated with a high level of physical activity were gender $(p<0.001)$, age $(p=0.02)$, waist-to-hip ratio (WHR) $(\mathrm{p}<0.001)$, sitting level $(\mathrm{p}=0.044)$ and occupational type $(\mathrm{p}<0.001)$. Conclusions: It was found that the participants displaying a high level of physical activity had a better quality diet that adhered to the Mediterranean diet but not to a significant degree. The variables associated with a high level of physical activity were male gender, younger age, normal WHR, non-sedentary occupation and reduced sitting time. The study findings could serve the purpose of improving future public health promotion of physical activity and the Mediterranean diet. Med Pr. 2019;70(2):169-76
\end{abstract}

Key words: physical activity, IPAQ-short questionnaire, workers, Mediterranean diet, MDS score, public health

Corresponding author: Sandra Pavičić Žeželj, Teaching Institute of Public Health of Primorsko-Goranska County,

Department of Health Ecology, Krešimirova 52a, 51000 Rijeka, Croatia, e-mail: sandra.pavicic-zezelj@zzjzpgz.hr

Received: April 20, 2018, accepted: September 10, 2018

\section{INTRODUCTION}

Despite the known health benefits of regular physical activity (PA) [1] habits, a large share of the European population is physically inactive [2]. Physical inactivity causes $6-10 \%$ of the major non-communicable diseases, including coronary heart disease and type 2 diabetes, as well as breast and colon cancer [3]. The 2005 Eurobarometer survey [4] showed that $59 \%$ of adult Croatians were physically inactive; in 2007 39\% of them were inactive [5], while the 2013 Eurobarometer survey conducted in 28 European countries [6] revealed that $21.6 \%$ of Croatians were inactive, which indicated a significant rise in PA among Croatians. Another Croatian PA study showed a rise in the number of metabolic equivalent (MET) minutes per week (MET-min/week) from 58.2 [7] to 78.7 [8] but the 2013 Eurobarometer survey [6] showed the Croatian average of $42.4 \mathrm{MET}-\mathrm{h} /$ week. The working population, aged $18-64$, is of special interest for public health monitoring and evaluation as workers' unhealthy habits may lead to significant individual, organizational, economic and social consequences due to sick leaves. In addition, the majority of working people spend, on average, one-third or more of their day at work, so their occupational PA may have a significant contribution to their total daily activity. Studies dealing with occupational and leisure-time PA and sitting habits revealed that high occupational activity was associated with a reduced risk of abdominal obesity [9] while leisure-time sitting might have a stronger association with obesity than occupational sitting. Another health problem is that, out of $28 \mathrm{EU}$ countries, Croatia has the highest prevalence of overweight among men [10]. In the light of public health, PA is often coupled with diet 
when it comes to dealing with non-communicable diseases which account for three quarters of total morbidity and mortality, both in the world and in Croatia [11]. In addition, one quarter of the Croatian examinees had unhealthy eating habits [12] and, with age, achieved a better quality diet, especially women [13-15] which showed that the female working-age population (aged 18-65) mostly had an unhealthy diet. Most health studies examine the diet-health relationship and are less focused on the relationship between physical activity and diet, especially in Croatia, which is an important public health program determinant. The World Health Organization's PA recommendations encourage an increased PA, not only in terms of quantity but also intensity, for additional health benefits [1].

The aim of this study was to determine diet quality and adherence to the Mediterranean diet (MD), according to the level of physical activity, and to detect variables associated with the high level of physical activity among the working population.

\section{MATERIAL AND METHODS}

\section{Participants}

This cross-sectional study covered full-time workers who visited the Institute for Occupational Medicine as part of their regular occupational health checks from March to July 2016. Out of 457 participants, 57 were excluded due to illness, and the remaining 400 participants, who had signed the informed consent for all study actions that were in accordance with the Declaration of Helsinki, were included. The Ethics Committee of the Teaching Institute of Public Health approved the study protocol.

\section{The questionnaire and physical activity assessment}

The study data was obtained from the questionnaire divided into 2 parts. The first part was about the participants' socio-demographic and work characteristics enabling the determination of sedentary and non-sedentary occupation types, and the occupational and leisure-time PA, using the short version of International Physical Activity Questionnaire (IPAQ-short) in the Croatian language [16] to assess the participants' scores for sitting, walking, moderate- and vigorous-intensity activities during the preceding 7 days. Based on the PA data, an estimated energy expenditure in MET-min/week was calculated according to the scoring protocol [16], by which the participants were divided into 3 groups as follows:
1. A high group which included participants who had done vigorous-intensity activity for at least 3 days and accumulated at least $1500 \mathrm{MET}$-min/week, or any combination of walking, moderate-intensity or vigorous intensity activities for 7 days, achieving a min. of $3000 \mathrm{MET}$-min/week.

2. A moderate group which included participants who had done vigorous activity for 3 or more days, at least 20 min per day, or $\geq 5$ days of moderate-intensity activity or walking, at least $30 \mathrm{~min}$ per day, or $\geq 5$ days of any combination of walking, moderate-intensity or vigorous intensity activities, achieving a min. 600 MET-min/week.

3. A low group which included participants who had not met any of the above recommendations.

\section{Dietary habits assessment}

\section{and Mediterranean Diet Score (MDS)}

The second part of the questionnaire was a validated Food Frequency Questionnaire (FFQ) for the Mediterranean diet-based populations [17], which was adapted and used for diet evaluation of the Croatian female population of the Primorsko-Goranska County [13]. The participants indicated their usual consumption frequency of 57 offered meals in the preceeding week, with options ranging from "never" to "more than 3 times a day," and the serving sizes that were specified as small, medium and large. It is well known that traditional dietary habits and lifestyles unique to the Mediterranean region lower the incidence of chronic diseases and improve longevity [18]. Therefore, assessing the adherence to the Mediterranean diet (MD) is of public health significance. Trichopoulou et al. [19] described Mediterranean Diet Score (MDS) as a tool for assessing the MD adherence on the basis of 9 characteristics of the traditional MD. The total MDS ranged from 0 showing the minimum adherence to the traditional MD to 9 showing the maximum adherence. A Mediterranean Diet Score of 0-3 indicated no adherence to the MD, 4-5 indicated medium adherence, and 6-9 - a good adherence to the MD.

\section{Anthropometric assessment}

Trained nurses measured the participants' body weight and height using an electronic scale (SECA, Germany), with weight accuracy of $\pm 0.1 \mathrm{~kg}$, and height accuracy of $\pm 0.5 \mathrm{~cm}$ that was used for the body mass index (BMI) calculation. The body mass index was categorized into underweight $\left(<18.5 \mathrm{~kg} / \mathrm{m}^{2}\right)$, normal weight (18.5$\left.24.99 \mathrm{~kg} / \mathrm{m}^{2}\right)$, overweight $\left(25-29.99 \mathrm{~kg} / \mathrm{m}^{2}\right)$ and obese 
$\left(\geq 30 \mathrm{~kg} / \mathrm{m}^{2}\right)$. Waist and hips circumferences were measured with a Seca 1 ergonomic tape (SECA, Germany) $(0-205 \mathrm{~cm})$ that was used for calculating the waist-tohip ratio (WHR). Waist circumference (WC) was categorized as increased (men $\geq 94 \mathrm{~cm}$, women $\geq 80 \mathrm{~cm}$ ) and WHR was categorized as large (men $>1.00$, women $>0.85)[20]$.

\section{Statistical analysis}

The normality of the study variables was tested using the Kolmogorov-Smirnov test. The categorical variables are shown as numbers and percentage rates, and the numerical variables - as means, standard deviation, medians and interquartile range. As the main aim was to display the differences in PA classes according to the IPAQ recommendations (the IPAQ guidelines) [16], the $\chi^{2}$ test, the 2-way analysis of variance (ANOVA) and the Kruskal-Wallis test were used for testing the differences between the categorical and numerical variables. In order to determine socio-demographic variables, anthropometric parameters and significant nutritional predictors of the high level of physical activity, hierarchical linear regression was applied. The significance level for all analyses was set at $\mathrm{p}<0.05$. All the data was statistically analyzed using the Statistical Package for the Social Sciences (SPSS) software, version 18 (SPSS Inc., USA), and the Dell Statistica software system, version 13 (Dell Inc., USA).

\section{RESULTS}

The characteristics of the study participants are presented in Table 1 according to the IPAQ recommendations [16] by 3 groups: low, moderate and high. The participants were mostly moderately physically active $(\mathrm{p}<0.000)$ and one-third of them were highly active. The majority of the participants were men (68\%) and they were statistically better represented in all PA groups $(p=0.004)$. The participants' median age was 36 years and the partic-

Table 1. Characteristics of the study participants who visited the Institute for Occupational Medicine in 2016 by physical activity groups

\begin{tabular}{|c|c|c|c|c|c|}
\hline Variable & \multicolumn{4}{|c|}{ Physical activity } & $\mathrm{p}$ \\
\hline Participants [n (\%)] & $400(100)$ & $32(8)$ & $220(55)$ & $148(37)$ & $<0.000^{\mathrm{a}}$ \\
\hline $\operatorname{men}[\mathrm{n}(\%)]$ & $272(68)$ & $24(75)$ & $128(58)$ & $120(81)$ & \multirow{2}{*}{$0.004^{\mathrm{a}}$} \\
\hline women $[\mathrm{n}(\%)]$ & $128(32)$ & $8(25)$ & $92(42)$ & $28(19)$ & \\
\hline non-sedentary occupation [n (\%)] & $204(51)$ & $12(3)$ & $92(23)$ & $100(25)$ & $0.002^{2}$ \\
\hline $\mathrm{BMI}\left[\mathrm{kg} / \mathrm{m}^{2}\right](\mathrm{M} \pm \mathrm{SD})$ & $25.5 \pm 3.7$ & $26.3 \pm 3.9$ & $26.0 \pm 5.1$ & $24.7 \pm 3.5$ & 0.127 \\
\hline \multicolumn{6}{|l|}{$\mathrm{WC}[\mathrm{cm}](\mathrm{M} \pm \mathrm{SD})$} \\
\hline men & $95.6 \pm 11.2$ & $94.3 \pm 12.7$ & $99.8 \pm 10.6$ & $91.3 \pm 9.8$ & $<0.000^{\mathrm{b}}$ \\
\hline men & $0.9(0.07)$ & $0.87(0.07)$ & $0.93(0.06)$ & $0.87(0.06)$ & $<0.000^{\mathrm{b}}$ \\
\hline women & $0.80(0.05)$ & $0.84(0.06)$ & $0.80(0.06)$ & $0.77(0.04)$ & $0.035^{\mathrm{b}}$ \\
\hline Total PA [min/week] (M (IQR)) & $600(480)$ & $420(120)$ & $560(180)$ & $1020(540)$ & $<0.000^{\mathrm{b}}$ \\
\hline LPA & $420(210)$ & $260(210)$ & $320(120)$ & $420(240)$ & $<0.000^{\mathrm{b}}$ \\
\hline MPA & $180(300)$ & $120(120)$ & $180(80)$ & $420(480)$ & $<0.000^{\mathrm{b}}$ \\
\hline VPA & $60(60)$ & $0(0)$ & $90(60)$ & $180(360)$ & $<0.000^{\mathrm{b}}$ \\
\hline MET-min/week & $1980(2850)$ & $1260(120)$ & $1620(540)$ & $4500(3420)$ & $<0.000^{\mathrm{b}}$ \\
\hline Sitting [min/day] (M (IQR)) & $300(120)$ & $360(60)$ & $300(60)$ & $240(60)$ & $0.000^{\mathrm{b}}$ \\
\hline
\end{tabular}

${ }^{a} \mathrm{p}$ values significant for group differences at $\mathrm{p}<0.05\left(\chi^{2}\right.$ test $)$.

${ }^{\mathrm{b}} \mathrm{p}$ values significant for group differences at $\mathrm{p}<0.05$ (ANOVA and the Kruskal-Wallis test).

BMI - body mass index, LPA - low physical activity, MET-min/week- metabolic equivalent-min per week, MPA - moderate physical activity, PA - physical activity,

VPA - vigorous physical activity, WC - waist circumference, WHR - waist-to-hip ratio. 
ipants with moderate PA habits $(\mathrm{p}=0.035)$ were significantly the oldest. There were slightly more participants with non-sedentary occupations (construction workers, cleaning service workers, waiters and waitresses, nurses, salespeople, sportspeople) and they were mostly in the high PA group $(\mathrm{p}=0.002)$, while the participants representing sedentary occupations (teachers, management staff, administrators, clerks, transport workers) had mostly low and moderate PA habits. On average, the participants were overweight. The participants with high PA habits had normal weight, while low and moderate PA group members were overweight. On average, all the participants, both men and women, had increased WC, while WHR in both genders was kept within the recommended range [20]. Men in the high PA group had significantly lower WC and WHR than in the other 2 groups ( $\mathrm{p}<0.001, \mathrm{p}<0.001$, respectively). Women in the high PA group had significantly lower WHR than in the other 2 groups $(p=0.035)$.
The participants' total PA was $600 \mathrm{~min} /$ week, and the high PA group spent twice as much time $(\mathrm{p}<0.000)$ on leisure-time PA. Low PA with an average of $420 \mathrm{~min} /$ week prevailed in all PA groups, moderate PA was 3 times more frequent in the high PA group than in the other 2 PA groups and vigorous PA was represented as taking $60 \mathrm{~min} /$ week in the moderate and high PA groups. The median MET-min/week was 1980 and 3177.60 on average. The median of $4500 \mathrm{MET}-\mathrm{min} /$ week in the high PA group was 2.8 times higher than in the moderate PA group $(\mathrm{p}<0.000)$ and 3.6 times higher than in the low PA group $(\mathrm{p}<0.000)$. Sitting time of the study participants was determined at $300 \mathrm{~min} /$ day, being statistically singificantly longer in the low PA group $(\mathrm{p}=0.000)$ than in the other 2 PA groups, with the highly active participants reporting to have spent less time sitting.

The participants' dietary habits, which are presented in Table 2, mostly adhered to the $\mathrm{MD}\left(\mathrm{Me}_{\mathrm{MDS}}=6\right)$, with the high PA group displaying the best adherence to the

Table 2. The study participants who visited the Institute for Occupational Medicine in 2016, including their energy, dietary variables intake and Mediterranean Diet Score (MDS) by physical activity groups

\begin{tabular}{|c|c|c|c|c|c|}
\hline \multirow{2}{*}{ Variable } & \multicolumn{5}{|c|}{ Physical activity } \\
\hline & overall & low & moderate & high & $\mathrm{p}$ \\
\hline Energy $[\mathrm{MJ}](\mathrm{M}(\mathrm{IQR}))$ & $8.1(4.5)$ & $8.4(6.6)$ & $8.2(4.5)$ & $7.8(4.6)$ & 0.676 \\
\hline Proteins [\%MJ] (M (IQR)) & $18.4(3.2)$ & $18.4(2.4)$ & $17.8(3.0)$ & $19.2(3.8)$ & $0.004^{\mathrm{a}}$ \\
\hline Lipids [\%MJ] $(\mathrm{M} \pm \mathrm{SD})$ & $33.7 \pm 4.1$ & $33.9 \pm 3.2$ & $33.5 \pm 4.9$ & $33.1 \pm 6.6$ & 0.460 \\
\hline Cholesterol [mg] (M (IQR)) & $415.1(256.5)$ & $318.9(262.9)$ & $377.1(223.0)$ & $466.8(391.3)$ & $0.000^{\mathrm{a}}$ \\
\hline Dietary fiber $[\mathrm{g}](\mathrm{M} \pm \mathrm{SD})$ & $18.9 \pm 7.4$ & $17.3 \pm 5.5$ & $18.2 \pm 7.2$ & $20.1 \pm 7.9$ & 0.173 \\
\hline Grains $[\mathrm{g}](\mathrm{M}(\mathrm{IQR}))$ & $214.3(192.1)$ & $216.8(411.1)$ & $225.7(190.0)$ & $211.4(161.4)$ & 0.141 \\
\hline Legumes [g] (M (IQR)) & $62.9(27.1)$ & $62.9(27.9)$ & $62.9(27.2)$ & $90(27.1)$ & $0.007^{\mathrm{a}}$ \\
\hline Milk and dairy products $[\mathrm{g}](\mathrm{M}(\mathrm{IQR}))$ & $386.4(262.8)$ & $467.8(306.4)$ & $388.5(274.2)$ & $351.4(225.7)$ & 0.065 \\
\hline Meat and meat products $[\mathrm{g}](\mathrm{M}(\mathrm{IQR}))$ & $232.6(148.3)$ & $205.4(326.2)$ & $236.1(144.3)$ & $244.9(142.3)$ & 0.709 \\
\hline Eggs [g] (M (IQR)) & $28.5(28.5)$ & $14.2(28.5)$ & $28.5(14.2)$ & $42.8(42.8)$ & $0.000^{\mathrm{a}}$ \\
\hline Fish $[\mathrm{g}](\mathrm{M}(\mathrm{IQR}))$ & $51.4(77.1)$ & $39.0(51.4)$ & $51.4(51.4)$ & $51.4(77.1)$ & 0.142 \\
\hline Vegetables [g] (M (IQR)) & $151.4(45.7)$ & $132.1(45.7)$ & $147.1(45.7)$ & $182.1(71.4)$ & $0.003^{\mathrm{a}}$ \\
\hline Potatoes [g] (M (IQR)) & $127.1(114.2)$ & $115.7(115.7)$ & $127.1(92.8)$ & $115.7(131.4)$ & 0.900 \\
\hline Fruit $[\mathrm{g}](\mathrm{M}(\mathrm{IQR}))$ & $137.1(94.3)$ & $81.8(162.9)$ & $120.0(85.7)$ & $154.2(102.8)$ & 0.092 \\
\hline Olive oil [ml] (M (IQR)) & $4.67(2.1)$ & $4.6(3.7)$ & $4.2(3.7)$ & $8.6(6.2)$ & $0.033^{\mathrm{a}}$ \\
\hline Sweets [g] (M (IQR)) & $89.1(75.8)$ & $51.8(136.1)$ & $86.4(97.9)$ & $55(88.6)$ & $0.001^{\mathrm{a}}$ \\
\hline Regular soft drinks [ml] (M (IQR)) & $57.1(57.1)$ & $28.5(57.1)$ & $57.1(71.4)$ & $0(57.1)$ & 0.062 \\
\hline Coffee $[\mathrm{ml}](\mathrm{M}(\mathrm{IQR}))$ & $15(5)$ & $15(6.08)$ & $15(5)$ & $10(7.9)$ & 0.157 \\
\hline Alcoholic beverages [ml] (M (IQR)) & $71.4(157.1)$ & $132.1(178.5)$ & $71.4(192.8)$ & $21.4(71.4)$ & $0.000^{\mathrm{a}}$ \\
\hline MDS (M (IQR)) & $6(2)$ & $5.50(1.50)$ & $6(2)$ & $7(2)$ & 0.113 \\
\hline
\end{tabular}

${ }^{a} \mathrm{p}$ values significant for group differences at $\mathrm{p}<0.05$ (ANOVA and the Kruskal-Wallis test). 
$\mathrm{MD}\left(\mathrm{Me}_{\mathrm{MDS}}=7\right)$. Although the high PA group had the smallest energy intake, its members had a statistically significantly greater intake of proteins $(\mathrm{p}=0.004)$, cholesterol ( $p=0.000)$, legumes ( $p=0.007)$, eggs $(p=0.000)$, vegetables $(p=0.003)$ and olive oil $(p=0.033)$. They also had statistically the lowest intake of alcoholic beverages $(\mathrm{p}=0.000)$. The intake of grains, milk and dairy products, as well as regular soft drinks and coffee was also the lowest in the high PA group but not to a statistically significant degree. In the low PA group the greatest intake of milk and dairy products, and the lowest intake of meat and meat products, fish, vegetables and fruit were noted but deemed insignificant. The moderate PA group showed significantly the greatest intake of sweets $(\mathrm{p}=0.001)$.

The results of hierarchical linear regression are shown in Table 3. The analysis of the obtained results showed that age $(p=0.008)$, gender $(p<0.001)$ and WHR $(p<0.001)$ were significant predictors of the high level of physical activity. The high level of physical activity was significantly negatively associated with age and WHR, and positively with gender. The body mass index and WC are not significant predictors of the high level of physical activity. After controlling age, gender, WHR, WC and BMI, the high level of physical activity was significantly positively associated with the sitting level $(\mathrm{p}=0.043)$ and the occupation type $(\mathrm{p}<0.001)$.

In the third step, after controlling the effects in the second step, age $(\mathrm{p}=0.02)$, WHR $(\mathrm{p}<0.001)$, the sitting level $(\mathrm{p}=0.044)$ and the occupational type $(\mathrm{p}<0.001)$ remained significant predictors, while the MDS is not a significant predictor of the high level of physical activity.

Table 3. A hierarchical regression analysis of the association of socio-demographic variables, anthropometric parameters and nutrition with high physical activity among the working population

\begin{tabular}{|c|c|c|c|c|}
\hline Step/Variable & $\beta$ & $\Delta \mathrm{R}^{2}$ & $\mathrm{R}^{2}$ & F \\
\hline Step 1 & & $0.17^{\star *}$ & $0.17^{\star *}$ & $16.65^{* *}$ \\
\hline age group & $-0.144^{*}$ & & & \\
\hline BMI & -0.068 & & & \\
\hline WHR & $-0.267^{\star \star}$ & & & \\
\hline Step 2 & & $0.04^{* *}$ & $0.21^{\star *}$ & $15.28^{* *}$ \\
\hline age group & $-0.132^{*}$ & & & \\
\hline gender & 0.101 & & & \\
\hline BMI & -0.032 & & & \\
\hline occupation type & $0.284^{* *}$ & & & \\
\hline Step 3 & & $0.00^{* *}$ & $0.21^{\star *}$ & $13.34^{* *}$ \\
\hline age group & $-0.130^{*}$ & & & \\
\hline gender & 0.102 & & & \\
\hline BMI & -0.032 & & & \\
\hline WHR & $-0.239^{\star *}$ & & & \\
\hline WC & -0.063 & & & \\
\hline sitting level & $0.102^{\star}$ & & & \\
\hline
\end{tabular}

${ }^{*} \mathrm{p}<0.05,{ }^{* *} \mathrm{p}<0.001$.

Abbreviations as in Tables 1 and 2 . 


\section{DISCUSSION}

In this study, the participants' average PA habits were greater than $300 \mathrm{~min} /$ week as recommended [21] but lower than the Croatian PA assessed by Jurakic et al. in 2014 [8] and they were more similar to Jurakic et al.s PA study conducted in 2009 [7]. A half of the participants reached the WHO moderate PA recommendations [1] and one-third of them were highly active, which was twice as low as assessed by Eurobarometer in 2013 [6]. It was found that male gender and younger age were independently associated with being highly active, which was comparable to Gerovasili et al. [6] and Jurakic et al.'s studies $[7,8]$ and so was the non-sedentary occupation type, which was consistent with a large Chinese study [22]. A decline in PA with age was detected, which was in line with other studies on PA according to age $[7,23]$. In this study, two-thirds of people aged less than 45, who belonged to the so-called Millennial Generation or Generation Y [24], were involved, which was associated with a greater willingness to do physical activity. The study participants were generally overweight, similar to the Croatian PA study conducted in 2014 [8] and the Southern Croatian Mediterranean diet study [15]. It was detected that workers with greater WHR were less likely to be highly active than those with normal WHR. Workers with large WC, and especially with large WHR, were less physically active, which is in accordance with large Finnish [25] and Swiss [26] studies with similar variables. The results of a Spanish study [27] showed that its physically active participants had lower BMI, better adhered to the MD and consumed more vegetables, fruit, legumes, cereals, fish and nuts, but less red and white meat, which was similar to this study's highly active participants. This study also showed that those who participated more in moderate to high levels of PA had Mediterranean dietary habits, which was similar to a recent Italian study [28] where they found that high adherence to the MD was associated with being highly active. The large Netherlands European Prospective Investigation into Cancer and Nutrition (EPIC-NL) cohort study [29] showed that physical inactivity was associated with unhealthy dietary patterns assessed with the MDS in their low and high educated participants, which was similar to the results of this study. Some of the study participants had a diet that certainly needed improvements, which was similar to the results obtained in the study by Marventano et al. [28]. Given that the participants of this study were mostly people of younger age, the results were similar to other studies that had shown that younger people had unhealthy eating habits [30].

This study was based on self-reported data which constitutes its limitation, and so does the relatively limited number of participants. Other potential PA confounders, such as socio-cultural, economic and smoking factors, were not taken into account. However, the study proves advantageous as it was the first Croatian study to examine the high PA habits' association to anthropometric and dietary factors. The study findings could improve future public health PA promotion and guidelines for Croatia and the whole region. Public health actions should be more focused on the workplace that represents an ideal place for promoting healthy diet since people spend most of their day in that environment, and diet education at workplace has had a positive impact on changing the eating habits and increasing workplace efficiency.

In addition, investigating PA and dietary habits by the clinic for occupational medicine purposes represents a good setting for conducting public health surveys as well as promoting health benefits of both PA and MD.

\section{CONCLUSIONS}

It was found that one-third of the participants were highly active and had a better diet quality, adhering to the Mediterranean diet but not significantly. The variables associated with the high level of physical activity included male gender, younger age, normal WHR, non-sedentary occupation and reduced sitting time.

Those findings suggest that messages about physical activity and the Mediterranean diet health benefits are progressively being used, which represents a significant public health message acknowledgment. Still, such health messages should be continuously promoted.

\section{REFERENCES}

1. World Health Organization. Global recommendations on physical activity for health. Geneva: The Organization; 2010.

2. Loyen A, Van Hecke L, Verloigne M, Hendriksen I, Lakerveld J, Steene-Johannessen J, et al. Variation in population levels of physical activity in European adults according to cross-European studies: A systematic literature review within DEDIPAC. Int J Behav Nutr Phys Act. 2016;13:72, https:// doi.org/10.1186/s12966-016-0398-2.

3. Lee I-M, Shiroma EJ, Lobelo F, Puska P, Blair SN, Katzmarzyk PT. Effect of physical inactivity on major non-communicable diseases worldwide: An analysis of burden of disease 
and life expectancy. Lancet. 2012;380(9838):219-29, https:// doi.org/10.1016/S0140-6736(12)61031-9.

4. European Commission, TNS Opinion \& Social, editors. Special Eurobarometer 246/Wave 64.3 [Internet]. Belgium: The Commission; 2010 [cited 2018 Feb 1]. Available from http://ec.europa.eu/commfrontoffice/publicopinion/archives/ebs/ebs_246_en.pdf.

5. European Commission, TNS Opinion \& Social, editors. Special Eurobarometer 283/Wave 67.3. Health and long-term care in the European Union [Internet]. Belgium: The Commission; 2007 [cited 2018 Mar 20]. Available from: http:// ec.europa.eu/commfrontoffice/publicopinion/archives/ ebs/ebs_283_en.pdf.

6. Gerovasili V, Agaku IT, Vardavas CI, Filippidis FT. Levels of physical activity among adults $18-64$ years old in $28 \mathrm{Eu}-$ ropean countries. Prev Med. 2015;81:87-91, https://doi. org/10.1016/j.ypmed.2015.08.005.

7. Jurakić D, Pedisic Z, Andrijasević M. Physical activity of Croatian population: Cross-sectional study using International Physical Activity Questionnaire. Croat Med J. 2009; 50(2):165-73, https://doi.org/10.3325/cmj.2009.50.165.

8. Jurakic D, Golubić A, Pedisic Z, Pori M. Patterns and correlates of physical activity among middle-aged employees: A population-based, cross-sectional study. Int J Occup Med Environ Health. 2014; 27(3):487-97, https://doi. org/10.2478/s13382-014-0282-8.

9. Steeves JA, Bassett DR, Thompson DL, Fitzhugh EC. Relationships of occupational and non-occupational physical activity to abdominal obesity. Int J Obes. 2012;36(1):100-6, https://doi.org/10.1038/ijo.2011.50.

10. Eurostat Statistics Explained [Internet]. Eurostat; 2017 [cited 2018 Mar 20]. Overweight and obesity - BMI statistics. Available from: http://ec.europa.eu/eurostat/statistics-explained/index.php/Overweight_and_obesity_-_BMI_statistics\#Body_mass_index.

11. Kralj V, Brkić Biloš I, Corić T, Silobrčić Radić M, Šekerija M. Kronične nezarazne bolesti - Teret bolesti stanovništva Hrvatske / Chronic non-communicable diseases - The burden of the population's disease in Croatia. Cardiol Croat. 2015;10:167-75, https://doi.org/10.15836/ccar.2015.167.

12. Jelinić JD, Pucarin-Cvetković J, Nola IA, Senta A, Milosević $M$, Kern J. Regional differences in dietary habits of adult Croatian population. Coll Antropol. 2009;33(1):31-4.

13. Jovanović GK, Zezelj SP, Malatestinić D, Sutić IM, Stefanac VN, Dorcić F. Diet quality of middle age and older women from Primorsko-Goranska County evaluated by healthy eating index and association with body mass index. Coll Antropol. 2010;34(2):155-60.

14. Kenđel Jovanović G, Pavičić Žeželj S, Krešić G, Cvijanović $\mathrm{O}$. Mediterranean diet in relation to body mass index and waist-to-hip ratio among sedentary group of Croatian workers from Mediterranean region. In: Frece J, editor. Proceedings of the Eight International Congress of Food Technologists, Biotechnologists and Nutritionists; 2014 Oct 21-24; Opatija, Croatia. Croatian Society of Food Technologists, Biotechnologists and Nutritionists; 2014. p. 166-73.

15. Kolčić I, Relja A, Gelemanović A, Miljković A, Boban K, Hayward C, et al. Mediterranean diet in the southern Croatia - Does it still exist? Croat Med J. 2016;57(5):415-24, http://doi.org/10.3325/cmj.2016.57.415.

16. International Physical Activity Questionnaire Group. Guidelines for data processing and analysis of the International Physical Activity Questionnaire (IPAQ) [Internet]. The Group; 2005 [cited 2018 Mar 1]. Available from: https://docs. google.com/viewer? $\mathrm{a}=\mathrm{v} \&$ pid=sites\&srcid=ZGVmYXVsdGRvbWFpbnx0aGVpcGFxfGd4OjE0NDgxMDk3NDU1YWRIZTM.

17. Martin-Moreno JM, Boyle P, Gorgojo L, Maisonneuve P, Fernandez-Rodriguez JC, Salvini S, et al. Development and validation of a food frequency questionnaire in Spain. Int J Epidemiol. 1993;22(3):512-9, https://doi.org/10.1093/ije/ 22.3.512.

18. Romagnolo DF, Selmin OI. Mediterranean diet and prevention of chronic diseases. Nutr Today. 2017;52(5):20822, https://doi.org/10.1097/NT.0000000000000228.

19. Trichopoulou A, Costacou T, Bamia C, Trichopoulos D. Adherence to a Mediterranean diet and survival in a Greek population. N Engl J Med. 2003;348:2599-608, https://doi. org/10.1191/1358863x04vm552xx.

20. World Health Organization. Obesity: Preventing and managing the global epidemic. Report of a WHO Consultation (WHO Technical Report Series 894). Geneva: The Organization; 2000.

21. Klonizakis M, Alkhatib A, Middleton G, Smith MF. Mediterranean diet and exercise induced improvement in agedependent vascular activity. Clin Sci. 2013;124(9):579-87, https://doi.org/10.1042/CS20120412.

22. Du H, Bennett D, Li L, Whitlock G, Guo Y, Collins R, et al. Physical activity and sedentary leisure time and their associations with BMI, waist circumference, and percentage body fat in 0.5 million adults: The China Kadoorie Biobank study. Am J Clin Nutr. 2013;97(3):487-96, https://doi. org/10.3945/ajcn.112.046854.

23. Moreno-Franco B, Peñalvo JL, Casasnovas Lenguas JA, LeonLatre M. Factores asociados al cumplimiento de las recomendaciones sobre actividad física en población trabajadora de entre 40 y 55 años de edad / Compliance with physical activity recommendations and associated factors in a cohort of spanish adult workers. Rev Esp Salud 
Publica. 2015;89(5):447-57, http://doi.org/10.4321/S113557272015000500003.

24. Lloyd T, Shaffer ML, Christy S, Widome MD, Repke J, Weitekamp MR, et al. Health knowledge among the millennial generation. J Public Health Res. 2013;28;2(1):3841, https://doi.org/10.4081/jphr.2013.e8.

25. Hu G, Tuomilehto J, Silventoinen K, Barengo N, Jousilahti P. Joint effects of physical activity, body mass index, waist circumference and waist-to-hip ratio with the risk of cardiovascular disease among middle-aged Finnish men and women. Eur Heart J. 2004;25(24):2212-9, https://doi. org/10.1016/j.ehj.2004.10.020.

26. Wanner M, Martin BW, Autenrieth CS, Schaffner E, Meier F, Brombach C, et al. Associations between domains of physical activity, sitting time, and different measures of overweight and obesity. Prev Med Rep. 2016;3:177-84, https://doi.org/10.1016/j.pmedr.2016.01.007.

27. Alvarez-Alvarez I, Zazpe I, Pérez de Rojas J, Bes-Rastrollo M, Ruiz-Canela M, Fernandez-Montero A, et al. Medi- terranean diet, physical activity and their combined effect on all-cause mortality: The Seguimiento Universidad de Navarra (SUN) cohort. Prev Med. 2018;106:45-52, https:// doi.org/10.1016/j.ypmed.2017.09.021.

28. Marventano S, Godos J, Platania A, Galvano F, Mistretta A, Grosso G. Mediterranean diet adherence in the Mediterranean healthy eating, aging and lifestyle (MEAL) study cohort. Int J Food Sci Nutr. 2018;69(1):100-7, https://doi.org/ 10.1080/09637486.2017.1332170.

29. Fransen HP, Boer JMA, Beulens JWJ, de Wit GA, Buenode-Mesquita HB, Hoekstra J, et al. Associations between lifestyle factors and an unhealthy diet. Eur J Public Health. 2017;27(2):274-8, https://doi.org/10.1093/eurpub/ckw190.

30. Inelmen EM, Toffanello ED, Enzi G, Sergi G, Coin A, Busetto L, et al. Differences in dietary patterns between older and younger obese and overweight outpatients. J Nutr Health Aging. 2008;12(1):38, https://doi.org/10.1007/BF02 982157.

This work is available in Open Access model and licensed under a Creative Commons Attribution-NonCommercial 3.0 Poland License - http://creativecommons.org/licenses/by-nc/3.0/pl/deed.en. 